\title{
Alguns Aspectos Essenciais sobre a Energia
}

\author{
JORGE VALADARES*
}

\begin{abstract}
Conscientes da existência de concepções empíricas incorrectas sobre a energia profundamente enraizadas na linguagem do dia a dia $e$ com conotações históricas, teremos que Ihe atribuir a importância que têm no processo de ensino-aprendizagem. Deveremos partir do conhecimento dessas concepções $e$ adoptar estratégias conducentes a rebater $e$ não reforçar, essas concepções incorrectas. Estas estratégias passam por um tratamento cuidado de alguns aspectos essenciais sobre a energia que vamos focar em seguida de um modo necessariamente breve mas exemplificativo.
\end{abstract}

\section{FORMAS FUNDAMENTAIS DE ENERGIA}

A energia é uma grandeza associada a todos os constituintes do universo desde a sua origem. Em escala crescente poderemos dizer que ela está associada aos quarks e leptões, aos hadrões, aos átomos e moléculas, às celulas, tecidos e órgãos, aos seres vivos e inanimados, às estrelas, planetas e cometas, às galáxias, aos enxames de galáxias e aos superenxames de galaxias. Em suma, a energia está associada a toda a matéria $e$ à radiação mas não se poderá confundir com elas.

Como a energia aparece associada a todas as manifestações de força e de movimento, ela intervém em todos os fenómenos, mecânicos, térmicos, ópticos, sonoros, etc. Está presente em todo o universo material e também no chamado universo fotónico acompanhando a radiação que enche todo 0 vazio de matéria. A energia constitui a essência da acção, já que todo 0 acto ou gesto, por mais insignificante que seja, envolve p. 59). Reparemos, por exemplo, nas designações energia calorifica, calor, fluxo calorífico, fluxo de energia calorífica, fluxo de energia térmica e energia térmica em trânsito. Não pretenderão todas significar 0 mesmo? Para 0 professor bem preparado, estas diferentes designações não constituern problema. Mas, no que se refere ao aluno, só servirão para o confundir. $E$, pior do que isto, se analisarmos a mesma designação, a energia térmica em varios livros, ela surge com significados distintos: nuns significa 0 mesmo que calor, noutros identifica-se com energia interna e noutros, ainda, procura traduzir uma parte da energia interna.

Porque não adoptar 0 principio de Guilherme de Ockham, séc. XVIII, segundo 0 qual "as entidades não deverão ser multiplicadas para além do necessário"? No que se refere à energia, há uma grande tendência para contrariarmos este princípio (Gailiunas, p.587). Ora, ganharse-ia imenso em clareza se se reduzissem os qualificativos aplicados à palavra energia, falando muito mais em transferências do que em formas de energia. Aliás, as formas essencialmente distintas de energia que se manifestam nos fenómenos vulgares com que lidamos são apenas duas:

- Energia cinética ou energia das partículas associada aos seus movimentos;

- Energia potencial, ou energia ligada às interacções partículas-campos.

Nos fenómenos relativistas manifesta-se uma outra forma fundamental de energia, a energia de massa, ou energia que as partículas possuem, mesmo em repouso e isoladas, "pelo simples facto de existirem" (Feynman, 1989, p. 91).

Estas formas básicas dc energia das partículas e dos campos existentes num dado sistema contribuem para a chamada energia interna, $U$, do sistema. Trata-se de uma grandeza termodinâmica que caracteriza 0 sistema em cada estado de equilíbrio e cuja variação, entre dois estados do sistema, só depende destes. É, pois, uma função termodinâmica de estado. A energia interna de um sistema varia sempre que o sistema sofre uma transformação de um estado para outro, devido a uma transferência de energia através da sua fronteira. Se considerarmos um sistema fechado, isto é, que não troca matéria com 0 exterior. a transferência de energia pode suceder por um processo mecânico e/ou por um processo térmico e/ou por um processo de radiação. 0 primeiro envolve a realização de um trabalho. 0 segundo envolve a transferência de calor através da fronteira e dá-se devido à existência de gradientes de temperatura. Pode ocorrer por condução ou por convexão. 0 último consiste na emissão ou recepção de radiação electromagnética. Tradicionalmente, 0 último processo estava englobado no segundo, isto é, a radiação era considerado um modo de transferência de calor. Porém, dadas as características particulares do processo de radiação e 0 facto de não envolver a necessidade de um suporte material, tem vindo a ser modernamente considerado em separado.

Não privilegiamos esta ou aquela abordagem da energia em particular, mas defendemos um rigor de linguagem por parte dos professores que passa pela abolição tanto quanto possivel dos qualificativos aplicados à energia, e de toda a conotação material. Mas esse rigor só terá repercussão nos alunos se Ihe forem proporcionadas situações de aprendizagem conducentes à incoerência das suas ideias com a realidade natural $\mathrm{e}$ experimentalmente vivida. É preferivel falar mais em transferências de energia e menos em formas de energia. Mas, ao discutirmos as transferências de energia, há que ter cuidado para não cairmos em análises desajustadas. Um exemplo: quando alguém fala ao telefone, que transformação e/ou transferência de energia ocorre? Uma resposta provável será: transformação de energia sonora em energia eléctrica. Esta resposta é incorrecta. Por um lado, é muito mais significativa a transferência de energia que antecede 0 acto de falar, do que a que corresponde ao acto de falar. A variação de energia potencial do telefone é considerável (principalmente se pegar- 
mos em todo o telefone), enquanto que a eficiência do microfone na passagem da energia do ar vibrante para o microfone é inferior a 1\% (Chishokn, 1992). E, além disso, também há que contar com a energia que aquece 0 ar e 0 microfone. $E$, por outro lado, tem de intervir energia eléctrica para amplificar 0 sinal. $E$, finalmente, a energia sonora não é mais do que energia mecânica de vibração das moléculas de ar, e 0 aluno fica com a ideia de que intervém uma qualquer forma misteriosa de energia que apenas tem que ver com o emissor da voz.

\section{A ENERGIA NO CORPO HUMANO}

Dissemos que todo o acto ou gesto, por mais insignificante que seja, envolve transferências de energia. Assim, consideremos, a título de exemplo, o acto diário de dormir. Mesmo durante 0 sono e em absoluto repouso, 0 corpo humano exerce uma actividade metabólica (actividade metabólica basal), na qual consome energia. A energia consumida por unidade de tempo é, em média (Manon e Hornyak, 1985, p. 196):

$$
\begin{gathered}
P=80 \mathrm{~W}=70 \mathrm{Cal} / \mathrm{h} \\
\left(1 \mathrm{Cal}=10^{3} \mathrm{cal}=1 \mathrm{kcal}\right)
\end{gathered}
$$

0 esqueleto e principalmente, 0 coração realizam trabalho, consumindo cerca de $25 \%$ dessa energia total metabólica. 0 cérebro continua em complexa actividade e consome cerca de $19 \%$ da energia total. Os rins consomem cerca de $10 \%$ da energia e 0 fígado e o baço cerca de $27 \%$. (Okuno, Caldas e Chow, 1982, p. 115). Além disso, emitimos e recebemos radiações, respiramos e transpiramos, pelo que trocamos energia com a atmosfera. 0 próprio sangue, ao circular nas veias, liberta energia.

A taxa metabólica do ser humano varia consoante 0 tipo de actividade que desenvolve: Assim temos, por exemplo, os seguintes valores médios (Marion e Hornyak, 1985, p. 196):
0 corpo humano é um sistema que obedece, como qualquer outro sistema na natureza, à lei da conservação da energia. No final de um dia, toda a actividade realizada pelo corpo humano corresponde a uma energia perdida para 0 exterior, o que se traduziria por um saldo negativo de energia relativamente ao ambiente, não fosse a indispensável actividade da alimentação e, com ela, o fomecimento ao corpo da energia necessária para "pôr o balancete em ordem".

A energia libertada na combustão dos produtos alimentares é aproximadamente 5 Cal por cada litro de oxigénio consumido, independentemente dos diversos valores calóricos desses produtos, conforme se pode ver na tabela seguinte (adaptada de Cameron, J.R. \& Skofronic, J.G. - Medical Physics, Addison-Wesley, 1978): conclusão que 0 valor da potência radiante não se afasta muito do valor da taxa metabólica basal, isto é, o corpo humano em repouso emite na forma de radiação praticamente a energia que absorve nas combustōes celulares.

Se a temperatura atmosférica for superior à da pele, 0 corpo recebe energia em quantidade superior à energia que emite. Mas sucede nessas condições que 0 corpo começa a transpirar e a evaporação acaba por remover 0 excesso de energia.

Vemos, por esta pequena referência que a energia desempenha um papel fundamental na vida. 0 corpo humano funciona como um sisterna que transfere energia aproveitando parte dela para a realização dos actos vitais. Esta desenrola-se de modo a que a energia total do universo se vai conservando e degradando simultaneamente.

\begin{tabular}{lcc}
\hline Substâncias & $\begin{array}{l}\text { Energia libertada por litro } \\
\text { de } \mathbf{O}_{2} \text { utilizado em } \mathbf{~} C \text { Cal/ } \mathbf{L}\end{array}$ & Valor calórico em $\mathbf{~ K C a l} / \mathbf{g}$ \\
\hline Glucose & 5,1 & 3,8 \\
\hline Carbohidratos & 5,3 & 4,1 \\
\hline Proteinas & 4,3 & 4,1 \\
\hline Gorduras & 4,7 & 9,3 \\
\hline Dieta típica & 5,0 & - \\
\hline
\end{tabular}

Uma vez que o oxigénio entra fundamentalmente pelos pulmões (apenas cerca de $2 \%$ é absorvido através da pele), a taxa metabólica acaba por ser controlada pelo ritmo e profundidade da respiração e pode medir-se a partir do volume de oxigénio consumido. Compreende-se assim que durante 0 repouso a nossa respiração seja lenta e pouco profunda, ao contrário do que sucede quando desenvolvemos uma actividade violenta em que a respiração é rápida e profunda.

A pele emite energia por meio de ondas electromagnéticas no domínio do infravermelho. A potência radiante emitida pode calcular-se por meio da lei de Stefan-Boltzmann e depende da temperatura da pele e da temperatura exterior. Feitos uns simples cálculos, chega-se à

\section{TAXAS METABÓLICAS}

\begin{tabular}{lrr}
\hline & Cal/h & watts \\
\hline No acto de dormir, descansar e a ouvir conferências & 70 & 80 \\
\hline Actividades leves (passear a pé, trabalho de casa) & 250 & 290 \\
\hline Actividades moderadas (passear de bicicleta, etc) & 450 & 520 \\
\hline Actividades pesadas (jogar basquetebol, etc) & 600 & 700 \\
\hline Actividades excessivas (só aguentáveis durante $1 \mathrm{~min}$ ) & 700 & 810 \\
\hline Actividades limites (só aguentáveis durante 10 s) & 1200 & 1400 \\
\hline
\end{tabular}

Abordando temas como este, da energia no corpo humano, ainda que necessariamente de um modo superficial, mostram aos alunos a importância do estudo da Fisica e da Química, em geral, e da energia em particular.

E dispomos, também, de uma oportunidade de combater a ideia alternativa segundo a qual os alimentos são energia e que ingerir alimentos é como que engolir energia. Os alunos passam a reconhecer a importância do oxigénio, e a sentir a energia como uma grandeza que acompanha todos os processos que ocorrem no corpo humano, que funciona como um sistema que a transfere. E passam a reconhecer que os alimentos, só por si, não serviriam para nada.

\section{O DESAPROVEITAMENTO DA ENERGIA NO NOSSO PLANETA}

A nossa vida está actualmente dependente de uma enorme e permanente desperdicio de energia nas fábricas, nos transportes, nas habitações, etc. Costuma-se mesmo tomar como um dos indices do nível de vida de um povo a "energia que ele consome" per capita. 
A taxa média de crescimento anual do consumo mundial de matérias primas energeticas foi (Direcção Geral de Energia, 1983, p.7):

$-2,2 \%$ entre 1925 e 1950 :

- $5 \%$ entre 1950 e 1975.

Nestes últimos anos, pese embora sentido de economizar as reservas dessas matérias primas, o consumo tem continuado a aumentar conforme se pode ver no quadro seguinte (boletim da OCDE, Statistiques et Bilans Energétiques Mondiaux. Paris, 1990):

CONSUMO DE ALGUMA MATÉRIAS PRIMAS ENERGÉTICAS

\begin{tabular}{lcccc}
\hline Ano & $\begin{array}{c}\text { Petróleo } \\
\text { (em Gkg) }\end{array}$ & $\begin{array}{c}\text { Carvão } \\
\text { (em Gkg) }\end{array}$ & $\begin{array}{c}\text { Gás natural } \\
\text { (em Mtep) }\end{array}$ & $\begin{array}{c}\text { Electricidade } \\
\text { (em Mtep) }\end{array}$ \\
\hline 1971 & 2395 & 2129 & 899 & 453 \\
\hline 1972 & 2573 & 2161 & 943 & 491 \\
\hline 1973 & 2777 & 2182 & 986 & 528 \\
\hline 1974 & 2730 & 2192 & 1008 & 542 \\
\hline 1975 & 2687 & 2356 & 1010 & 561 \\
\hline 1976 & 2860 & 2399 & 1054 & 602 \\
\hline 1977 & 2972 & 2494 & 1096 & 630 \\
\hline 1978 & 3088 & 2546 & 1133 & 664 \\
\hline 1979 & 3132 & 2677 & 1214 & 693 \\
\hline 1980 & 3101 & 2726 & 1228 & 716 \\
\hline 1981 & 2925 & 2719 & 1256 & 729 \\
\hline 1982 & 2798 & 2829 & 1253 & 737 \\
\hline 1983 & 2781 & 2827 & 1265 & 769 \\
\hline 1984 & 2862 & 2964 & 1374 & 812 \\
\hline 1985 & 2828 & 3127 & 1426 & 847 \\
\hline 1986 & 2958 & 3206 & 1462 & 871 \\
\hline 1987 & 2975 & 3288 & 1543 & 912 \\
\hline 1988 & 3093 & 3371 & 1608 & 950 \\
\hline & & & & \\
\hline
\end{tabular}

Destes recursos, o petróleo é aquele cujos gastos mais se têm conseguido controlar nos últimos anos. 0 conquase ininterruptamente. Ora as reservas mundiais provadas destas fontes de energia, já com dados de finais de 1992 , são relativamente escassas ( $B P$ Junho de 1993): 0 esforço que se tem desenvolvido no sumo dos outros tem vindo a aumentar Statistical Review of World Energy.

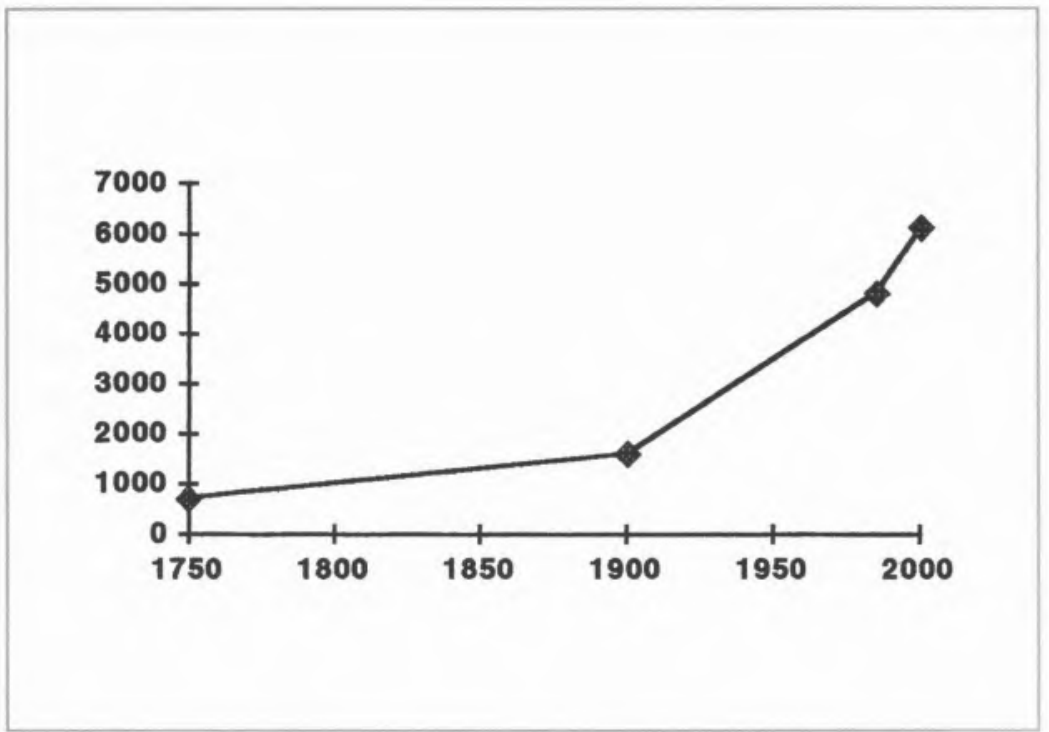

Por outro lado o crescimento da população tem sido avassalador, conforme se pode ver no gráfico, já com a previsão para 0 ano 2000, que é de 6116 milhões de habitantes (International Year Book 1987, p.9):

Dados recentes apontam para uma procura global de energia, por meados do próximo século, cerca dc 4 vezes superior à actual. Mas este valor poderá ser reduzido a metade se tirarmos partido de sistemas eficientes de aproveitamento (Starr, Searl, Alpert, 1992, p.981). Qual a conclusão a tirar destes dados? As reservas de combustiveis tradicionais são esgotáveis a relativamente curto prazo.

Em face do exposto, sentimos, pois, a necessidade absoluta de "racionalizar o consumo de energia", o que significa na prática duas coisas:

- reduzir ao maximo o consumo desses combustiveis (utilizar economicamente 0 automóvel, as máquinas electrodomésticas e 0 fogão, isolar os edificios, dispô-los adequadamente aquando da sua construção. etc);

- recorrer 0 mais possível à ener-

\section{RESERVAS DE ALGUMAS MATÉRIAS PRIMAS ENERGÉTICAS EM FINAIS DE 1992}

\begin{tabular}{lcrc}
\hline Região & Petróleo (em Gkg) & Carvão (em Gkg) & Gás natural $\left(\mathbf{e m ~} \mathbf{T m}^{3}\right)$ \\
\hline América do Norte & 5000 & 249183 & 7400 \\
\hline América Latina & 17500 & 11430 & 7300 \\
\hline Europa da OCDE & 2200 & 96924 & 5300 \\
\hline Restante Europa & 8100 & 315449 & 55600 \\
\hline Médio Oriente & 89500 & -62271 (total & 43100 \\
\hline África & 8300 & de Afr. e M.0.) & 9700 \\
\hline Ásia e Austrália & 5900 & 303925 & 9500 \\
\hline Total mundial & 136500 & 1039182 & 138300
\end{tabular}
como sejam o sol, o vento, as marés e a biomassa.

Devemos ter consciência que toda a energia que se utiliza na Terra se fica a dever, em última análise, ao Sol. Este astro irradia $3,9.10^{23} \mathrm{~J}$ de energia para 0 espaço em cada segundo, mas desta enorme quantidade, apenas a pequenissima fracçāo $5 / 10^{10}$ atinge a Terra. Esta pequeníssima fracção, mesmo assim, ainda corresponde a uma potência de aproximadamente $1370 \mathrm{~W}$ que atinge cada metro quadrado da alta atmosfera. Destes $1370 \mathrm{~W} / \mathrm{m}^{2}$ que atingem a superfície da atmosfera, são retidos apenas $1000 \mathrm{~W} / \mathrm{m}^{2}$. Com efeito, aproximadamente $37 \%$ da energia que incide na atmosfera é reflectida para o espaço exterior (albedo da Terra).

Dos 1000 W por metro quadrado que ficam retidos na Terra, apenas cerca de $1 / 3$ atinge a crusta. Esta radiação que atinge a crusta é, em parte, radiação proparte é difundida pela atmosfera. Esta energia que atinge a crusta varia ao longo do ano e depende da transparência da atmosfera, da latitude e da altitude. Em Portugal metropolitano, num dia quente de Verão, calcula-se que a energia recebida em cada segundo pela crusta é aproximadamente $315 \mathrm{~J}$ por cada metro quadrado (Bartels e Angenheister, 1970). A crusta não absorve toda a radiação que nela incide. A neve, a areia, as charnecas, os prados, os bosques e 0 mar reflectem essa radiação. Mas mesmo assim, a energia que atinge a crusta terrestre, se fosse convenientemente aproveitada, sobraria largamente para as necessidades, já que gia disponivel nas fontes alternativas, veniente directamente do Sol, e outra 
constitui 10000 vezes as necessidades do consumo mundial das actividades humanas. Mas, infelizmente, só uma percentagem insignificante desta energia é actualmente aproveitada de um modo directo. Esse aprovitamento directo da energia solar faz-se por dois processos essenciais, que constituem outros tantos ramos da investigação actual em aproveitamento da energia solar:

- por conversão térmica em sistemas activos (colectores solares) e passivos (estufas, casas solares, etc),

- por conversão eléctrica (nos painéis fotovoltaicos).

A parte restante da radiação tem as seguintes finalidades: a fotossintese, que inicia os ciclos da matéria orgâanica e da energia; a evaporação da água, que inicia 0 ciclo hidrológico:

- a criação de diferenças de temperatura atmosférica geradores do vento, 0 qual, em interaç̧ão com a hidrosfera vai transportar 0 vapor de água e gerar as ondas e as correntes marítimas;

- a emissão de radiação térmica, bem como a transformação em biomassa e em jazigos de combustiveis fósseis, sendo este 0 destino final temporalmente longínquo da radiação solar.

Se 0 aproveitamento artificial pelo homem da energia solar é muito pequeno, 0 aproveitamento natural pelos seres vivos também o é. Sabemos que os fotões solares fornecem energia fundamental para que as plantas verdes, por fotossintese, criem os seus alimentos. Mas essas plantas convertem apenas $0,5 \%$ da energia solar que recebem em materia orgânica. Os herbívoros aproveitam apenas $17 \%$ da matéria vegetal na sua alimentação. E os carnívoros, ao alimentarem-se dos herbivoros, apenas aprovei$\operatorname{tam} 4,4 \%$ da sua matéria. Os animais e plantas, ao morrerem, acabam por originar, por decomposição, os nu-trientes que irão servir de alimento a outras plantas. A decomposição anaeróbia acaba por originar, ao fim de muitos milhares de anos, os combustiveis fósseis. Estes, no fundo, acabam por ser os depositórios da energia que, há muitos milhões de anos, foi emitida pelo Sol para a Terra.

0 ciclo de transferências de energia na biosfera é um ciclo aberto, pois requere que seja transferida energia do Sol para as plantas verdes, únicas aproveitadoras da energia fotónica para sintetizar a matéria orgânica. $E$ trata-se, de facto, de um ciclo muito pouco eficiente do ponto de vista energético.
Sem a energia vinda do Sol também não haveria gradientes de temperatura atmosférica que estão na origem dos ventos cuja energia se explora. As quedas de água, de onde tanta energia se aproveita, fazem parte de um ciclo em que também desempenha papel fundamental a energia proveniente do Sol. A energia proveniente do Sol é, pois, imprescindivel para a vida no planeta Terra. Mas este desaproveita-a em altíssimo grau...

\section{ENERGIA, UM CONCEITO A CONSTRUIR}

"É imporlante compreender que, na Fis/ca actual, não temos conhecimento do que é a energia". Esta afirmação é de um dos maiores físicos do nosso século. Richard Feynman. De facto, o conceito de energia é um conceito altamente abstracto, abrangente e diferenciado, que tem imediatamente subordinado a ele conceitos como o de forma fundamental de energia, transformação de energia, transferência de energia conservação de energia e degradação de energia. Há muitos modos de conceptualizar esse conceito (Duit, 1985, p. 68) e é impossivel, quanto a nós, apresentar uma definiçāo que satisfaça em absoluto. A conhecida definição de Rankine, "energia é a capacidade de realizar trabaIho", ainda que seja a menos má revelase restritiva e enganadora. Restritiva porque associa por demais a energia à produção de trabalho, dando uma imagem mecanicista e pouco abrangente da energia. Enganadora, porque sabemos bem que nos processos espontâneos a energia conserva-se mas não se conser- va "a capacidade de realizar trabalho".

Se é impossivel afirmarmos, com toda a necessária abrangência 0 que a energia é, já se torna fácil afirmar aquilo que ela não é. Assim, e de modo sucinto, poderemos afirmar que (ao contrário do que muita gente pensa) a energia não é:

- uma força movente nem qualquer outro tipo de força;

- algo que esteja obrigatoriamente associada aos seres vivos e particularmente ao homem;

- a causa dos movimentos ou outros quaisquer fenómenos que ocorrem;

- nenhum combustivel seja ele 0 carvão, o petróleo, ou qualquer outro; nenhum alimento, seja este mais ou:

- menos "calórico";

- um fluido em repouso ou em movimento, seja ele uma queda de água ou ar em movimento;

- um reagente ou produto de reacções químicas;

- uma máquina ou qualquer outro mecanismo concreto.

A energia é uma quantidade que intervém em todos os fenómenos do Universo, e está associada às duas grandes realidades que nele existem: matéria e radiação. Um pedaço de matéria ou um feixe de radiação são "coisas" com determinadas propriedades que os caracterizam e distinguem. Uma dessas propriedades é a energia. Esta não se pode identificar nem com o pedaço de matéria nem com o feixe de radiação. Alguém identificaria um pedaco de água do mar com a sua densidade?

Há diversas estrategias para 0 ensino da energia que pôem ênfase em aspectos diferentes: umas são mais conceptuais-analíticas, com a tónica nos

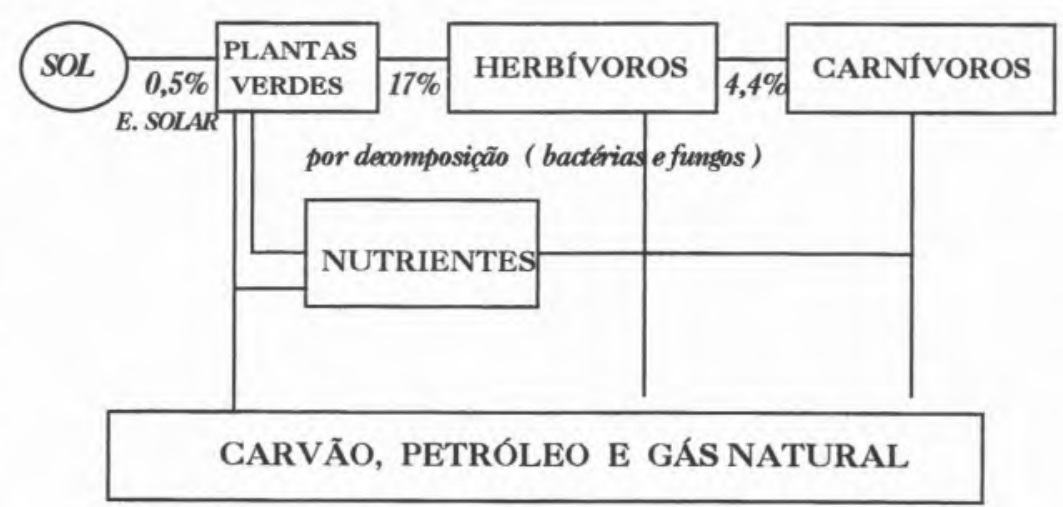


conceitos e formalismos; outras são mais fenomenológicas com os alunos em intensa interacção com os fenómenos, reais e provocados: outras, ainda, são fundamentalmente utilitárias com um tratamento predominante numa perspectiva industrial e económica; e, finalmente, há as abordagens sociais com ênfase na interacção ciência-tecnologia-sociedade (Driver e Millar, 1985 , pp. 16-21). Mas, em todas elas, o conceito de energia irá sendo construído por cada aluno, com muitas hesitações e imprecisões. É muito difícil aos alunos, com toda a informação que recebem diariamente acerca da energia, encararem essa grandeza como uma simples quantidade mensurável, que se conserva em todas as transformações. Veem-na preferencialmente como um mecanismo. uma substância, um fluido ou qualquer outro ente corpóreo que se gasta, e que é a causa das coisas acontecerem.

\section{A CONSERVAÇÃO DA ENERGIA}

A ideia actual de que a energia é um invariante matemático nos sistemas isolados levou muito tempo a ser fundamentada e passou, sem dúvida, pela descoberta de que se trata de uma grandeza que é multl-facetada isto é manifesta-se nos mais variados fenómenos da natureza. Os cientistas aprenderam a medir as variações da energia de um sistema, servindo-se de relações que envolvem quantidades efectivamente mensuráveis como velocidades, distâncias, forças, cargas eléctricas, etc. E verificaram. ou melhor induziram a partir da experiência que, quando um sistema passa por uma série de transformações, não há criação ou destruição de energia. Se o sistema está isolado a soma total das variações de energia que sofre é zero, e portanto a energia interna mantém-se. Se o sisfema não está isolado então a soma total das variações da sua energia interna é igual à energia total que o sistema troca com o exterior.

Para ilustrar o significado de energia, e ao mesmo tempo revelar o carácter tautológico da lei da conservação da energia, Feynman recorre a uma alegoria reveladora da sua criatividade (1971, pp. 4.1-4.2):

A mãe de Daniel, o travesso oferece-lhe 28 blocos indestrutiveis para brincar e, dia após dia, por mais que ele pretenda esconder alguns dos blocos, a mãe acaba sempre por descobrir o seu número, quer eles estejam fechados numa caixa, escondidos na água suja de um tanque, ou ocultos de qualquer outro modo. E verifica que a quantidade de blocos permanece invariante. Com 0 aumento gradual da complexidade das "brincadeiras" do Daniel, vai surgindo a necessidade de introduzir termos abstractos para determinar a quantidade total de blocos, termos esses que envolvem grandezas mensuráveis como massas de caixas, volumes de água, etc.

Ora a natureza, no que respeita à energia, comporta-se de modo muito semelhante, ainda que de forma mais abstracta já que a energia não é corpórea, não é formada por blocos materiais. Recomendamos vivamente a exploração didáctica desta alegoria de Feynman.

0 princípio da conservação da energia serve de referencial ao estudo dos mais diversos fenómenos. Por exemplo, com base nele e possivel deduzir-se muito facilmente as equações dos circuitos eléctricos, estudar-se 0 comportamento termoquímico dos sistemas, estudaremse as condições de equilibrio nas máquinas simples, etc. E é importante que a aprendizagem proporcionada aos alunos dê esta ideia de coerência e integridade das ciências físicas.

Defendemos, pois, que, para além dos circuitos eléctricos, muitos outros temas sejam tratados tendo por referencial esse conceito unificador e abrangente que é a energia. Os alunos deverão tomar consciência de que muitos resultados que estabelecem (ou deviam estabelecer...) experimentalmente não são mais do que corolários dessa afirmação muito geral que é o princípio da conservação da energia.

0 trabalho e 0 calor deverão ser encarados como grandezas que medem a energia transferida através das fronteiras dos sistemas. No que respeita à grandeza trabalho realizado por uma força que actua num corpo, logo a seguir à sua definição,

$$
W=\int_{1}^{2} \vec{F} \cdot d \vec{r}
$$

deverá vir a sua relação com a variação da energia que, por si só, provoca no corpo:

$$
W=\Delta E
$$

Só com uma atenção permanente à lei da conservação da energia será possível contrariar-se a tendência para incorrecções que aparecem em livros de texto
(Bauman, 1992, p.264) e em que professores e alunos acabam por cair. Bauman refere 0 exemplo da da lei do trabalhoenergia que aparece muitas vezes enunciada na forma: "o trabalho realizado num corpo é igual a variação da sua energia cinética".

Se substituirmos a palavra corpo pela palavra partícula, a afirmação está correcta. Tal como ela está escrita, é incorrecta, pois o trabalho realizado pelas forças exteriores que actuam num corpo é igual à variação total da energia que, por si só, provoca no corpo (incluindo a variação da sua energia interna), e não, necessariamente, á variação apenas da sua energia cinética. Aliás um simples exemplo serve para mostrar a incorrecção: no choque de uma bola de plasticina com uma parede, o trabalho das forças exteriores é nulo (não deslocam o seu ponto de aplicação pois a parede não se desloca) e a velocidade do corpo reduz-se a zero, isto é, tem-se

$$
W=0 \text { e } \Delta E_{c}<0 \text {, portanto } W \neq \Delta E_{c}
$$

Também devemos ter consciência do carácter claramente tautológico do princípio da conservação da energia. A fé neste princípio é tal que, sempre que parece estar a ser violado, logo se inventa uma nova porção de matéria ou energia para justificar a energia em falta. Assim sucedeu quando Pauli, em 1931 sugeriu a existência do neutrino, para compatibilizar 0 declínio $\beta$ com 0 principio da conservação da energia. Só mais tarde a existência desta particula viria a ser comprovada experimentalmente.

Analisemos, a terminar, a lei da conservação da energia nos casos em que há uma variação significativa na energia de massa (Valadares, 1993).

Consideremos uma reacção nuclear em que, por exemplo, a soma das massas dos produtos é inferior à soma das massas dos reagentes. 0 "deficit de massa", $\Delta m$, dá lugar à libertação de uma energia $\Delta m c^{2}$. 0 que se costuma afirmar é que "a massa foi convertida em energia". Mas tal afirmaçāo é confusa para não dizer incorrecta. De facto, de acordo com Einstein,

"a massa inercial de um sistema de corpos deve ser encarada precisamente como uma medida da sua energia". (1984, p.45).

e

"massa e energia são essencialmente idênticas: elas são apenas expres- 
sões diferentes da mesma entidade". (1958, p.61).

Então imaginemos que a reaç̧ão ocorre dentro de paredes perfeitamente isoladoras que retêm os fotões e outras radiações quaisquer que se libertem. A energia do sistema, assim isolado, não varia pela lei da conservação da energia. logo a massa do sistema, que the é equivalente, também não varia. Se uma e outra não variam, como pode haver conversão de uma noutra?! Nem a energia equivalente à soma das massas das partículas do sistema, nem a soma das energias cinéticas das partículas, se mantiveram invariáveis (como, aliás, não se mantêm em geral nas interacçōes). A parte do conteúdo de energia do sistema correspondente às partículas diminuiu. Mas em compensação apareceu uma parte do conteúdo energético do sistema na forma de radiação. A massa-energia total é sempre a mesma, só que está desigualmente repartida antes e após a reacção.

Se definirmos o sistema de outro modo (apenas as partículas e não a radiação emitida) então a radiação é perdida para 0 exterior e o sistema não está isolado. Neste caso a massa diminui, e portanto a energia de massa, e também diminui o conteúdo de energia do sistema. Não se trata de transformação de massa em energia, mas variações paralelas dessas duas grandezas equivalentes.

De acordo com o principio da conservação da energia, num sistema isolado de corpos a energia é um invariante no tempo. Ora, como a energia e a massa são duas grandezas absolutamente equivalentes, "as duas faces de uma mesma moeda", a conclusão que há que tirar é a de que a massa nos sistemas isolados é também um invariante no tempo. Podemos, pois, afirmar citando Einstein, que

"o postulado da conservação da massa de um sistema coincide com o da conservação da energia e só é válido na medida em que o sistema não absorve nem emite energia" (1984, p. 45).

Não há conversões de matéria, em energia ou de energia em matéria como tantas vezes se ouve referir, por exemplo nas reacções de "materialização" ou de "desmaterialização" (Baierlein, 1991). Se tal sucedesse, estariamos perante 0 facto insólito de corpos, "coisas" reais existentes (matéria), se converterem num atributo ou propriedade (energia), que é uma entidade abstracta, um "constructo" da mente humana, e não nos deveríamos espantar, por exemplo, se vissemos água do mar a converter-se em densidade.

\section{A DEgRAdAÇÃO DA ENERGIA}

A exemplo do que sucedeu com a ideia de conservação de energia, a de degradação de energia também levou muito tempo a construir-se. Podemos afirmar que a sua história remonta aos tempos em que o homem começou a aproveitar as mais diversas máquinas para a realização de trabalho útil, particularmente a máquina a vapor. Recomendamos a leitura bastante formativa dessa história, para iniciarmos o domínio do importante conceito de degradação da energia.

Vamos tentar alinhar algumas conclusões a que os físicos chegaram acerca da energia:

$1^{a}-E m$ todos os processos que naturalmente ocorrem na natureza, uma dada quantidade de energia vai-se dlssipando isto é, espalhando cada vez por maior número de particulas. Assim, por exemplo, a energia dos fotões que atingem as plantas com clorofila que existem num prado vai-se sucessivamente espalhando pelas moléculas dessas plantas e pelo ar, pelas moléculas dos animais que pastam nesse prado, pelos animais que se alimentam desses animais, pela Terra, quando todos estes seres vivos morrem, e novamente pela atmosfera devido aos gases de putrefacção, etc.

$2^{\mathrm{a}}$ - Sempre que se produz um certo trabalho, por pequeno que seja ocorre em geral uma grande dissipação de energia. Um exemplo: sempre que da energia de algumas moléculas de gasolina e oxigénio que penetram nos cilindros de um automóvel, se produz um certo trabalho, exercido na cambota, há um aquecimento enorme do material do motor e do ar circundante, 0 qual é devido à dissipação de energia através das inúmeras moléculas que constituem esses corpos.

$3^{a}-$ - A energia mecânica é convertivel integralmente em calor mas o calor jamais é reconvertido integralmente em energia mecânica. Para retransformar este calor em energia mecânica há que fornecer o calor à fonte quente de uma máquina térmica (a caldeira no caso da máquina a vapor, 0 cilindro no caso do automóvel). Este tipo de máquina. porém, nunca apresenta um rendimento de $100 \%$, isto é, nunca é capaz de transformar todo 0 calor em energia mecânica. Uma grande parte do calor é transferido para uma fonte fria (o condensador, quando existe, ou a atmosfera). Por exemplo, nas primitivas máquinas a vapor só cerca de $9 \%$ do calor era transformado em energia mecânica, o restante aquecia a máquina e 0 ar (grande dissipação de energia!) Hoje um rendimento de $40 \%$ já e considerado muito bom.

$4^{\mathrm{a}}-\mathrm{A}$ energia quando concentrada produz efeitos que não são possiveis quando em igual ou mesmo maior quantidade se encontra dissipada. Assim, por exemplo, quando se fornece uma certa energia à água de um tanque até ela ficar tépida e se introduz nele um ovo, este não consegue ser cozido. Porém, se concentrarmos a mesma energia fornecida à água do tanque em um ou dois decilitros de água contidos numa panela (fornecendo o mesmo calor as duas quantidades de água) já conseguimos cozer 0 ovo.

$5^{a}$ - Há um sentido para os fenómenos espontâneos do ponto de vista das transferências de energia. Assim, já todos observámos, por exemplo, um copo de vidro cair ao chão e estilhaçar-se. A energia potencial gravítica converte-se em energia cinética do copo durante a queda. No momento do impacto com 0 solo, a energia transfere-se para os estilhaços e para 0 ar circundante, dissipando-se deste modo.

Mas já alguém viu o "filme ao contrário" isto é, acontecer espontaneamente 0 fenómeno inverso? E note-se que este fenómeno inverso não é teoricamente impossivel no quadro da conservação da energia. Com efeito, imaginemos esse fenómeno inverso a ocorrer, os pedaços de vidro a concentrarem-se novamente no local de queda, a reconstituirem o copo, toda a energia que se tinha espalhado a concentrar-se novamente no copo na forma cinética, e o copo a subir novamente até ao ponto de onde caíu, com uma reposição da energia potencial inicial a partir da energia cinética. Se este fenómeno inverso ocorresse, não teriamos uma cadeia de transferências de energia oposta, e, portanto sempre com a mesma energia total? A lei da conservação da energia continuaria válida! Então por que motivo esse fenómeno inverso nunca se observou?

Durante muito tempo pensou-se que era a energia a grandeza responsável por 
os fenómenos ocorrerem esponta-neamente no sentido em que ocorrem, e não no sentido oposto. Alguns cientistas chegaram mesmo a afirmar que um sistema evolui espontaneamente no sentido em que a sua energia diminui. Segundo esta ideia, os regatos descem espontaneamente as montanhas porque assim é libertada energia, as reacções ocorrem espontaneamente no sentido em que se liberta calor, etc. Mas, já há muito se verificou que este critério é falso. Há processos espontâneos que são endoenergéticos (são exemplos a evaporação da água e a reacção do hidrogénio com o iodo para dar iodeto de hidrogénio, entre muitos outros).

0 critério de espontaneidade dos fenómenos não tem que ver com a energia, mas, sim, com uma outra grandeza fimdamental chamada entropia.

Foi Clausius quem introduziu esta grandeza e mostrou que, se um sistema evolui de um estado 1 para um estado 2 então a variação da entropia é $\Delta S$ tal que

$$
\Delta S \geq \int_{1}^{2} \frac{d Q}{T}
$$

Desta desigualdade de Clausius conclui-se, imediatamente, que nos sistemas isolados $(d Q=0)$ a variação de entropia só pode ser positiva ou nula

$$
\Delta S \geq 0
$$

isto é, quando um sistema isolado evolui, a entropia do seu estado final nunca pode ser menor do que a do seu estado inicial.

Esta lei determina precisamente 0 sentido da evolução espontânea dos sistemas isolados que é o do aumento da sua entropia que acompanha as transformações irreversiveis que nele ocorrem.

0 facto de 0 critério de espontaneidade nas transformações de um sistema isolado ser 0 aumento da sua entropia não significa que esse critério seja válido para os sistemas não isolados. Um sistema (S) que evolui trocando energia com o seu ambiente (A) pode sofrer transformações espontâneas com diminuição da sua entropia. Isto passa-se, por exemplo, na formação espontânea de cristais numa solução. A espontaneidade do processo não requere que a entropia do sistema, $\Delta S_{s}$, aumente mas, sim, que a entropia do universo do sistema, $\Delta S_{u}$ aumente. Há muitos casos análogos ao da cristalização, em que se tem

$$
\begin{aligned}
& \Delta S_{U}=\Delta S_{S}+\Delta S_{A}>0 \\
& \text { ainda que seja } \Delta S_{S}<0
\end{aligned}
$$

Os sistemas isolados evoluem no sentido do aumento da entropia que é, também, o sentido dos estados mais prováveis. A mecânica estatística tornou possivel associar a qualquer estado termodinâmico (macroscópico) de um sistema (definido por um pequeno número de variaveis de estado como a pressão e a temperatura, por exemplo) uma probabilidade, $\pi$, que está relacionada com 0 número de estados dinâmicos (microscópicos) correspondentes (dependentes das posições e movimentos de todas as particulas que constituem 0 sistema). $\mathrm{E}$ Boltzmann estabeleceu a seguinte relação entre a entropia de cada estado (propriedade termodinâmica já anteriormente definida por Clausius) e a respectiva probabilidade:

$$
\begin{gathered}
S=k_{B} \ln \pi \\
\left(k_{B} \text { é a constante de Boltzmann }\right)
\end{gathered}
$$

0 estado inicial do sistema copoTerra-ar ambiente (quando o copo está inteiro, a uma dada altura do solo) é muito menos provável, e portanto tem menor entropia, do que o estado do mesmo sistema quando o copo está estiIhaçado no chão. Neste estado final mais provável, e portanto de maior entropia a energia encontra-se dissipada e mais desordenada. Se no estado inicial era possivel realizar algum trabalho útil (por exemplo, levantar um corpo leve ligando-0 ao copo por um fio passando por uma roldana fixa), no estado final a capacidade de realizar trabalho diminuiu.

Em resumo, a entropia é uma grandeza muito importante que:

- mede a probabilidade de ocorrêncla dos estados de um sistema;

- quantifica a dispersão da energia total;

- taduz a capacidade de se realizar traballho útil a partir da energia do sistema.

Um sistema isolado evolui espontaneamente de modo a que a energia se vá mantendo constante, mas esse sistema vá passando por estados cada vez mais prováveis e, portanto, de maior entropia. A energia no sistema vai-se dissipando, a entropia vai aumentando, e cada vez é menor a probabilidade de se realizar trabalho útil a partir dessa energia.

Num sistema não isolado, acontece 0 mesmo com 0 universo do sistema (sistema mais ambiente).

Quando, para concretizar, uma central termoeléctrica concentra uma certa porção de energia nas cargas que constituem a corrente eléctrica que fornece, dissipa na realidade, uma muito maior quantidade de energia na atmosfera. Ocorre, pois, uma nítida dissipação da energia global consumida pela central, a que Tait chamou degradação da energia e que é acompanhada pelo aumento da entropia do universo.

0 facto de ocorrer degradação da energia na central não significa que a energia foi consumida ou gasta. Assim, a energia proveniente da combustão, após uma série de transferências a que ficou sujeita, acabou por se manter invariante no final destas. Porém, encontra-se em grande parte dispersa e desordenada já que foi aquecer os fumos, 0 ar atmosférico, as paredes dos materiais, etc. (a esta energia desorganizada ou desordenada Brunhes chamava energia sem valor).

Apenas uma pequena parte da energia transferida pela central fica concentrada e ordenada nos electrões dos fios eléctricos (a esta energia Brunhes chamava energia-riqueza). É esta que, posteriormente, vai ser aproveitada para a realização de trabalho ou para posterior degradação (por exemplo em aquecimento dos fios). Considerando todo 0 universo da central, poderemos afirmar que a entropia deste aumenta à medida que a central vai funcionando.

A degradação ocorre porque a entropia aumenta e, com ela, a quantidade de energia dispersa e desordenada com menor capacidade de produzir trabalho útil. $E$ isso deve-se à irreversibilidade das transformações naturais...

\section{A ENERGIA E A SOCIEDADE}

A ciência e a tecnologia forneceu à humanidade meios extraordinários de bem-estar, desde os meios de transporte até aos meios de comunicação, desde os sistemas de iluminação até aos de aquecimento. etc. Porém, também Ihe proporcionou meios poderosos de auto-destruição. Quer nuns quer noutros, a energia não podia deixar de estar no cerne. Graças a ela, ocorrem grandes transformações na superficie terrestre. Uma das mais perigosas tem que ver com a composição da própria atmosfera.

Todas as transferências naturais de energia conduzem a um equilíbrio entre a radiação solar absorvida pela Terra e a emitida para o espaço exterior. A existên- 
cia na atmosfera terrestre de determinados gases produz um efeito de estufa que impede que determinadas radiações sejam reenviadas para 0 espaço, mantendo-se assim a temperatura da superfície da Terra. Sem a presença desses gases, a temperatura média da superfície terrestre seria inferior em cerca de $30^{\circ} \mathrm{C}$ ao que é actualmente. A contribuição dos diferentes gases para 0 efeito de estufa constam da figura seguinte (Physics rio catrastófico que corresponderia à subida da temperatura global do globo acima de um valor crítico, se a concentração dos gases do efeito de estufa subisse acima de determinados valores. Mas há que consciencializar o ser humano para o facto de o seu domínio da energia ter alterado 0 seu poder. Exige-se uma cultura diferente, adequada à época em que vivemos, capaz de responsabilizar cada ser humano pela conserva-

\begin{tabular}{|c|c|c|c|c|c|}
\hline & $\mathrm{CO}_{2}$ & $\mathbf{C H}_{4}$ & No & $\mathrm{CFC}_{11}$ & $\mathrm{CFC}_{12}$ \\
\hline \multirow[t]{2}{*}{$\begin{array}{l}\text { Potencial relativo } \\
\text { de aquecimento global }\end{array}$} & . & - & 园 & & \\
\hline & 1 & 21 & 290 & 3900 & 7300 \\
\hline \multirow[t]{2}{*}{$\begin{array}{c}\text { Concentraçáo } \\
\text { atmostérica média (ppm) } \\
\text { em } 1988\end{array}$} & & 口 & - & & \\
\hline & 350 & 1.7 & 0.31 & 0.00036 & 0.00044 \\
\hline \multirow[t]{2}{*}{$\begin{array}{l}\text { taxa de aumento } \\
\text { em } 1990\end{array}$} & $\Delta$ & & $\Delta$ & & \\
\hline & 0.4 & 1 & 0.3 & 5 & 4 \\
\hline
\end{tabular}

Contribuição de alguns gases para o efeito de estufa

Education, vol. 27, n 4, 1992).

A quantidade de dióxido de carbono na atmosfera tem vindo a crescer, em virtude do funcionamento das fábricas, dos carros, etc. De 280 p.p.m. (por milhão) no século transacto, passou a cerca de 340 p.p.m. actualmente. Esta alteração da composição da atmosfera poderá implicar uma alteração perigosa no efeito de estufa.

Dados recentemente divulgados numa exposição sobre 0 aquecimento global no Museu Americano de História Natural, em Nova lorque, mostram que desde 1880 até 1987 se verificou uma subida da temperatura média do globo de $0,5^{\circ} \mathrm{C}$ (Revkin, 1992, p.60).

Ainda não está demonstrado, de forma inequivoca, que 0 aumento das concentrações dos gases do efeito de estufa estão a produzir um aumento de temperatura (Physics Education, vol. 27, $n^{\circ} 4,1992$, p. 196). Mas é um facto que seis dos mais quentes anos, desde que há registos de temperaturas, são posteriores a 1980.

Não cabe aqui apresentar um cená- ção da "aldeia" de todos, capaz de consciencializar para o facto de a energia estar na base do perigo, quer de um holocausto nuclear, quer de uma destruição ecológica do nosso planeta, para não falar de outros perigos. Se, felizmente, no primeiro aspecto, a situação parece ter melhorado nestes últimos anos, 0 mesmo não se pode dizer a respeito dos outros perigos. Os poluentes lançados na atmosfera pelas fábricas (e não só), 0 dióxido de carbono, $\mathrm{CO}_{2}$, o dióxido de enxofre, $\mathrm{SO}_{2}$, os óxidos de azoto, $\mathrm{NO}_{\mathrm{x}}$, etc. poderão produzir 0 aquecimento global do planeta, a destruição da camada de ozono e as chuvas ácidas. Estes são alguns dos problemas relacionados com a energia que devem preocupar qualquer cidadão culto, já que está em risco a sua saúde e a dos restantes seres vivos e até mesmo a sobrevivência da raça humana. Por isso, tais temas não poderão deixar de ser debatidos num ensino que se pretende focado na interacção ciência-tecnologia-sociedade, e tendo como meta a preparação de cidadãos responsáveis.

\section{CONCLUSÃo}

A energia é uma grandeza abstracta de que os alunos ouvem falar permanentemente de um modo bastante concreto. A linguagem do dia a dia traduz algumas concepções incorrectas acerca da energia que foram tratadas num anterior artigo do mesmo autor. Essas concepções incorrectas têm origem histórica e, do mesmo modo que a ciência teve dificuldade em as clarificar, também os alunos apresentarn grandes dificuldades em as debelar.

Muitas vezes as estratégias e a linguagem adoptadas nas aulas, principalmente nos primeiros anos de escolaridade, em vez de contribuirem para a mudança conceptual que se pretende, ainda acabam por reforçar essas concepções incorrectas. Este artigo procura exemplificar algumas abordagens possiveis bem como o tipo de linguagem a adoptar, além de reforçar aspectos hoje considerados fundamentais no ensino da ciência como sejam os que têm que ver com a interacção ciência-tecnologia-sociedade.

\section{* Universidade Aberta Av. Duque d'Ávila, $1993-8^{\circ}-1000$ Lisboa}

\begin{abstract}
A tep (tonelada equivalente de petróleo) é uma unidade definida convencionalmente como sendo igual a 10 gigacalorias, que é aproximadamente a energia que corresponde a uma tonelada de petróleo (in Dicionário de Terminologia Energética da Associação Portuguesa de Energia, $2^{\mathrm{a}}$ ed., 1992).
\end{abstract}

\section{BIBLIOGRAFIA}

C. Adkins, An introduction to Thermal Physics, Cambridge University Press, Cambridge, 1987.

G. Alcaine, Rev. Esp. Fis. 3 (1) (1989) 59-62.

J. Bartels, G. Angenheister, Geofísica, Ed Meridiano, Lisboa, 1970.

P. Black, J. Solomon, Life-world and science world - pupils' ideas about energy, Entropy in the School, Vol. 1, Roland Eotvos Physical Society. Budapest, 1983.

J. Bliss, J. Ogborn, Eur. J. Sci. Educ. 7 (1985) 195-203.

A. Brook, Children's understanding of ideas about energy: a review of the literature, Energy Matters (proceedings of an Invited Conference), University of Leeds, 1985.

A. Brook, R. Driver, Driver and Millar (Editores), 
Aspects of secondary students' understanding of energy, Children's Learning in Science Project, University of Leeds, 1984.

B. Brunhes, La Dégradation de l'Energie, Ed. Flammarion, 1908.

D. Chisholm, Phys. Educ. 27 (1992) 215-220.

R. Driver, R. Millar, Teaching energy in schools: towards an analysis of curriculum approaches, Energy Matters (proceedings of an Invited Conference), University of Leeds, 1985.

R. Duit, In search of an energy concept, Energy Matters (proceedings of an Invited Conference). University of Leeds, 1985

R. Duit, Physics Education 19 (1984) 59-66.

A. Einstein, $A$ inércia de um corpo será dependente do seu conteúdo energético?. Textos Fundamentais da Física Moderna, $1^{\circ}$ Vol.- 0 Princípio da Relatividade, F. Calouste Gulbenkian, pp. 87-90, 1972.

A. Einstein, Sobre la teoria de la relatividad especial y general, Alianza Editorial, Madrid, pp. 42 46, 1984.

A. Favieres et al., Una introduccion al concepto de energia baseada en las ideas previas de los estudiantes, Comunicação OR--25 do $1^{\circ}$ Encontro Ibérico sobre o Ensino da Física, Valladolid, 1991.

R. Feynman, The Feynman Lectures of Physics,
Ed. Fondo Educativo Interamericano, S.A., Vol. 1Mecânica, radiação e calor, Bogota, pp. 4-1 a 412, 1971.

R. Feynman, 0 que é uma lei fisica?, Ed. Gradiva, Lisboa, 1989.

E. Fermi, Termodinâmica, Ed Almedina, Coimbra, pp. 28-58, 1973

F. Fernandes, Bol. Soc. Port. Quim. 6 (1981) 4.

C. Gayford, Eur. J. Sci. Ed. 8 (1986) 443-450

P. Gailiunas, Sch. Sci. Rev. (1988) 587-590.

J. Gilbert, M. Pope, Res. Sci. Tech. Ed. 4 (1986) 61-76.

S. Mak, S, K. Young, Sch. Sci. Rev. (1987) 464 470

J. Marion, J. Hornyak, General Physics with Bioscience Essays, Ed. John Wiley \& Sons, New York, 1985.

J. Ogborn, Sch. Sci. Rev. (1986)

J. Ogborn, Sch. Sci. Rev. (1990)

E. Okuno, I. Caldas, C. Chow, Física para Ciências Biológicas e Biomédicas, Harbra Ed. , São Paulo, 1982

T. Russel, H. Munley, Robin Millar (Editor), Science as a discipline, science as seen by stu- dents and teachers' professional knowledge, in Doing science: images of science in Science Education, ed. , The Falmer Press, London, 1989

F. Selleri, 0 que é a energia, Edit. Notícias, Lisboa, s/d R. Sexl, Eur. J. Sci. Ed. 3 (1981) 285-289,

J. Skea, Energy and environment, Phys. Educ. 27 (1992) 193-197

J. Solomon, Eur. J. Sci. Ed. 5 (1983) 49-59.

B. Stead, Energy, Learning in Science Project, University of Waikato, New Zealand, 1980.

M. Summers, Sch. Sci. Rev. (1983) 670-76.

K. Taber, Sch. Sci. Rev. (1989) 57-62.

R. Trumper, International Journal of Science Education 12 (1990) 343-354

J. Valadares, D. Pereira, Didáctica da Física e da Química, Universidade Aberta, Volumes 1 e 2 . Lisboa, pp.48-49 e 141-164, 1991.

J. Valadares, Gaz. Fis. 16-1 (1993) 9-14

J. Warren, Eur. J. Sci. Ed. 4 (1982) 295-297.

D. Watts, Phys. Educ 18 (1983) 213-217.

D. Watts, J. Gilbert, Stud. Sci. Ed. 10 (1983) 61-98.

M. Zemansky, The Physics Teacher (1970)

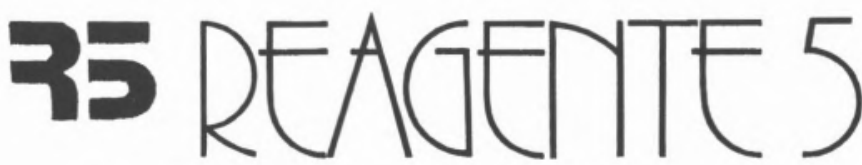

\section{QUÍMICA E ELECTRÓNICA, LDA.}

AV FERNÄO MAGALHÃES, 481 - 4300 PORTO

APARTADO $4710-4102$ PORTO CODEX

TELEFS, (02) $5102694 \bullet 5102696 \bullet 5103113$

FAX (02) 5102695 - TELEX 28167 REQUEL

DELEGAÇÃO:

RUA ALFREDO RUAS, 51A - PEDERNAIS - 2675 ODIVELAS

TELEF. (01) 9338801 - 9341417 - FAX (02) 9344116

Sistemas modulares de cromatografia líquida de alta pressão

- Cromatógrafos de fase gasosa

- Turbidímetros de alta precisão

- Medidores digitais de pH, portáteis e de bancada

- Espectrofotómetros de absorção atómica
- Aparelhos para destilação, desionização e ultra-purificação de água

- Fotómetros de chama para determinação de $\mathrm{Na}, \mathrm{Li}, \mathrm{Ca}$ e Ba

- Espectrofotómetros, estufas, centrífugas, agitadores, etc. 